\title{
Inborn errors of metabolism and motor disturbances in children
}

\author{
A. García-Cazorla • N. I. Wolf • M. Serrano • \\ B. Pérez-Dueñas $\cdot$ M. Pineda $\cdot$ J. Campistol $\cdot$ \\ E. Fernández-Alvarez $\cdot$ J. Colomer $\cdot$ S. DiMauro $\cdot$ \\ G. F. Hoffmann
}

Received: 18 March 2009/Submitted in revised form: 20 July 2009 / Accepted: 23 July 2009 / Published online: 30 August 2009

(C) SSIEM and Springer 2009

\begin{abstract}
Summary Motor disturbances are very common in paediatric neurology. Often families can be reassured that these are just variants of normal development. However, abnormal movements can also be the
\end{abstract}

Communicating editor: Jean-Marie Saudubray

Competing interests: None declared

In memory of Professor Robert Surtees, our friend and outstanding colleague in the field of paediatric neurology and neurometabolic diseases.

A. García-Cazorla $\cdot$ M. Serrano · B. Pérez-Dueñas ·

M. Pineda $\cdot$ J. Campistol $\cdot$ E. Fernández-Alvarez $\cdot$

J. Colomer

Neurology and Metabolism Department,

Hospital Sant Joan de Déu,

Barcelona, Spain

A. García-Cazorla $\cdot$ M. Serrano $\cdot$ B. Pérez-Dueñas •

M. Pineda $\cdot$ J. Campistol $\cdot$ E. Fernández-Alvarez $\cdot$

J. Colomer

Centre for Biomedical Research on Rare

Diseases (CIBER-ER), Instituto de Salud Carlos III,

Madrid, Spain

\section{N. I. Wolf}

Department of Child Neurology,

VU University Medical Center,

Amsterdam, The Netherlands

\section{S. DiMauro}

Department of Neurology,

Columbia University Medical Center,

New York, NY 10032, USA

\section{G. F. Hoffmann}

University Childrens Hospital Heidelberg,

Heidelberg, Germany

\section{A. García-Cazorla $(\triangle)$}

Neurology Department, Hospital Sant Joan de Déu,

Passeig Sant Joan de Déu, 2,

08950 Esplugues, Barcelona, Spain

e-mail: agarcia@hsjdbcn.org hallmark of severe brain dysfunction of different and complex origins. This review concentrates on motor disturbances as frequent and important symptoms of inborn errors of metabolism. A structured diagnostic approach is developed taking into account age-dependent physiological developments and pathophysiological responses of gross and fine motor functions. A series of investigations are presented with the primary aim of early diagnosis of treatable conditions. The correct recognition and differentiation of movement disorders (ataxia, rigid akinetic syndrome ('parkinsonism'), dystonia, athetosis, tremor, and others), spasticity, and neuromuscular disorders, requires profound neurological expertise. A high level of suspicion and close interaction between paediatric neurologists and specialists in inborn errors of metabolism are indispensable to effectively and timely identify patients in whom motor disturbances are the presenting and/or main symptom of an inborn error.

\begin{tabular}{|c|c|}
\hline \multicolumn{2}{|c|}{ Abbreviations } \\
\hline CNS & central nervous system \\
\hline CPK & creatine phosphokinase \\
\hline CTX & cerebrotendinous xanthomatosis \\
\hline GLUT-1 & glucose transporter type 1 \\
\hline НHН & $\begin{array}{l}\text { hyperammonaemia, hyperornithinaemia, } \\
\text { homocitrullinuria }\end{array}$ \\
\hline IEM & inborn error of metabolism \\
\hline MERRF & myoclonic epilepsy with ragged red fibres \\
\hline MSUD & maple syrup urine disease \\
\hline MNGIE & myoneurogastrointestinal encephalopathy \\
\hline MTP & mitochondrial trifunctional protein \\
\hline NARP & neuropathy ataxia and retinitis pigmentosa \\
\hline NPC & Niemann-Pick type C \\
\hline PKAN & pantothenate kinase \\
\hline PLA2G6 & phospholipase A2G6 \\
\hline
\end{tabular}




\section{Introduction}

Abnormal movements can refer to subtle physiological variants of normal development or can be caused by severe brain dysfunction. Furthermore, they are an almost constant feature in childhood encephalopathies whatever their origin might be. Inborn errors of metabolism (IEMs) frequently involve motor function not only because of the many anatomical regions that participate in this complex task, but also because they require perfect neurochemical interactions. The primary motor cortex (frontal lobe), and secondary motor cortices (e.g. parietal lobe) generate and transform neuronal impulses that control the execution of movement. The basal ganglia and cerebellum interact and regulate these signals that travel down the corticospinal tract through the spinal white matter to interact with interneurons and motor neurons in the spinal cord ventral horn. These ventral horn neurons send their axons through the ventral roots to individual muscle fibres. Each motor neuron in the spine is part of a functional unit called the motor unit. The motor unit is composed of the motor neuron, its axon, and the muscle fibres it innervates. Consequently, IEMs affecting motor cortex, basal ganglia, cerebellum, myelin, motor neurons, axons, muscle, or neuromuscular junctions or any of the interactions between them, can cause abnormal movements or disturbed locomotion. From a clinical point of view we can classify these motor abnormalities into movement disorders, spasticity, peripheral neuropathy, and muscle disorders. Because the last group corresponds to an extensive highly specialized field, it will not be considered in this review. As a rule, in IEMs, a combination of diverse motor signs will be present in most individual disorders (Table 1).

\section{Movement disorders}

Our understanding of paediatric movement disorders is rapidly evolving stimulated by progress in the discovery of monogenic neurogenetic disorders and consecutively the development of structured diagnostic and therapeutic approaches. In neurometabolic disorders causing abnormal movements, investigations of specific metabolites can give important clues to diagnoses in addition to the clinical presentation. A logical series of investigations should be followed with the primary aim of early diagnosis of treatable conditions. In this part we will concentrate on the main causes of ataxia, dystonia, and other movement disorders.

\section{IEMs and ataxia}

Ataxia is defined as an inability to maintain normal posture and smoothness of movements while force and sensation are intact. There are many variations in the clinical phenotype, ranging from consequences of pure cerebellar dysfunction (Poretti et al. 2008) to mixed patterns of brain involvement (extrapyramidal pathways, brainstem, and/or cerebral cortical involvement). A wide range of molecular defects have been identified, all involving the spinocerebellar pathways and without metabolic abnormalities. IEMs present a less frequent cause of ataxias and can be clinically classified following a pragmatic approach based on the clinical evolution: intermittent or episodic, stable or progressive ataxias (Prasad et al. 2005). Figure 1 proposes a diagnostic algorithm.

\section{Intermittent/episodic ataxias}

If due to a neurometabolic disorder, these are mainly diseases of intermediary metabolism. Ataxia is a frequent sign during acute/subacute decompensations of amino acids (such as MSUD disease; Holmgren et al. 1980) and organic acid and urea cycle disorders. Usually, these disorders have other neurological or extraneurological markers. By contrast, defects of energy metabolism presenting with intermittent ataxia may involve exclusively the nervous system and may be more difficult to diagnose. This is the case of respiratory chain disorders, e.g. the NARP syndrome, pyruvate dehydrogenase deficiency, and biotinidase deficiency. In NARP syndrome, isolated mental retardation may precede the appearance of episodic ataxia by years. Furthermore, once ataxia appears it tends to remain constant, with worsening during episodes of decompensation. Carbohydrate- and fever-sensitive ataxia is a feature of mild pyruvate dehydrogenase deficiency (Robinson et al. 1996). Biotinidase deficiency may also give rise to intermittent ataxia. High plasma lactate and other characteristic biochemical features of these disorders may be present only intermittently.

GLUT1 deficiency can present with intermittent ataxia as the only finding, mimicking other episodic ataxias. In this disease ataxia usually worsens before meals. Some children improve greatly with frequent carbohydrate-rich snacks and may not even need a strict ketogenic diet (Wang et al. 2005). Intermittent ataxia can also be seen in Hartnup disease; additional symptoms are pellagra-like skin changes, photic dermatitis, and psychiatric symptoms (Kleta et al. 2004). Recently a new cause of intermittent ataxia and 
mental retardation due to urocanic aciduria in a patient with mutations in the urocanase gene has been described (Espinós et al. 2009).

The so-called 'episodic ataxias' may be mistaken for metabolic disorders, although they belong to the channelopathies (Jen 2008). Correct diagnosis is important, as effective treatment exists. As a rule, metabolic parameters may be normal between bouts of ataxia in inborn errors of metabolism; testing is therefore mandatory when patients are symptomatic and usually involves CSF investigations. An important non-metabolic differential diagnosis for intermittent ataxia is intoxication, especially with benzodiazepines and other centrally acting drugs. Moreover, in a child with acute ataxia it is obviously mandatory to exclude more frequent aetiologies such as infectious diseases and opsoclonusmyoclonus syndrome.

Ataxias with progressive spinocerebellar dysfunction

The best example of this group is Friedreich's ataxia. The main additional clinical symptoms are polyneuropathy and pyramidal tract lesions and cardiomyopathy. Vitamin E deficiency and abeta-/hypobetalipoproteinaemia can also result in retinopathy, neuropathy, ophthalmoplegia, progressive mental retardation, and cardiomyopathy. Ataxia with vitamin E deficiency (AVED; Mariotti et al. 2004; Marzouki et al. 2005) is caused by mutations in the gene for alpha-tocopherol transfer protein. Laboratory findings include low-to-absent serum vitamin $\mathrm{E}$ and high serum cholesterol, triglycerides, and beta-lipoprotein. High doses of vitamin E (400-1200 IU/day) improve the neurological function. Abetalipoproteinaemia is a rare disorder due to a dysfunction in the microsomal triglyceride transfer protein gene $(M T P)$. Acanthocytosis on peripheral blood smears is a constant finding. Decreased serum LDL and VLDL and increased HDL cholesterol levels are present together with low triglyceride levels. High-dose supplementation of vitamin E has a beneficial effect on neurological symptoms (Homer et al. 2005). IOSCA (infantile-onset spinocerebellar ataxia) represents one of the most severe forms of recessive ataxias. It is characterized by progressive atrophy of the cerebellum, brainstem, and spinal cord and sensory axonal neuropathy (Table 1). It has been related to mitochondrial depletion syndromes (Hakonen et al. 2008). Cerebrotendinous xanthomatosis can also manifest as spinocerebellar ataxia (Siebner et al. 1996).

Ataxias with progressive neurological deterioration

Other disorders presenting with chronic (progressive) ataxia are Refsum disease, sphingolipidoses, L-2- hydroxyglutaric aciduria, cerebrotendinous xanthomatosis, and coenzyme $\mathrm{Q}_{10}$ deficiency. The degree of neurological deterioration depends on the disorder. In some cases the clinical picture may remain stable. Coenzyme $\mathrm{Q}_{10}$ deficiency may produce non-progressive ataxia as the only neurological manifestation. Highdose coenzyme $\mathrm{Q}_{10}$ supplementation is effective in some cases. Some phenotypes of GLUT-1 deficiency are characterized by chronic non-progressive ataxia, with intermittent fluctuations associated with fasting (Overweg-Plandsoen et al. 2003). The list of diseases to be included in this group is wide. Among them is also Niemann-Pick disease type C (NPC) and other neurodegenerative disorders; however, other signs of progressive neurological dysfunction as dementia usually become prominent.

Interestingly, in 4-hydroxybutyric aciduria and some forms of congenital disorders of glycosylation, ataxia may improve rather than deteriorate.

Ataxias with progressive myoclonic epilepsy

MERRF syndrome, Lafora disease, and neuronal ceroid lipofuscinoses are typical representatives of this group. Severe epilepsy is the clinical hallmark (Buccoliero et al. 2003). Ataxia and myoclonic epilepsy are also a feature of some lysosomal disorders such as the juvenile form of Gaucher disease (type 3), NPC, and sialidosis type 1 .

\section{IEMs and other movement disorders}

Other than ataxia, movement disorders in children may be divided into rigid akinetic syndrome ('parkinsonism') and dyskinetic movements (dystonia, athetosis, tremor, chorea, myoclonus, tic, and stereotype) (Fernández-Alvarez 2001). Tics are very rarely related to IEMs. Important movement disorders in IEMs are dystonia, secondary parkinsonism, chorea, tremor, and myoclonus (see Fig. 2). Different movement disorders may coexist in the same patient with an IEM. In children with an IEM, movement disorders are often dystonic (Assmann et al. 2003). In general, diseases causing parkinsonism in adults, may present with dystonia in children. Some neurometabolic disorders require metabolic studies of CSF metabolites for diagnosis (Table 2; Hoffmann et al. 1998).

Rigid akinetic syndrome and IEMs

Metabolic disorders causing primarily a rigid-akinetic syndrome include: (1) neurotransmitter deficiencies 


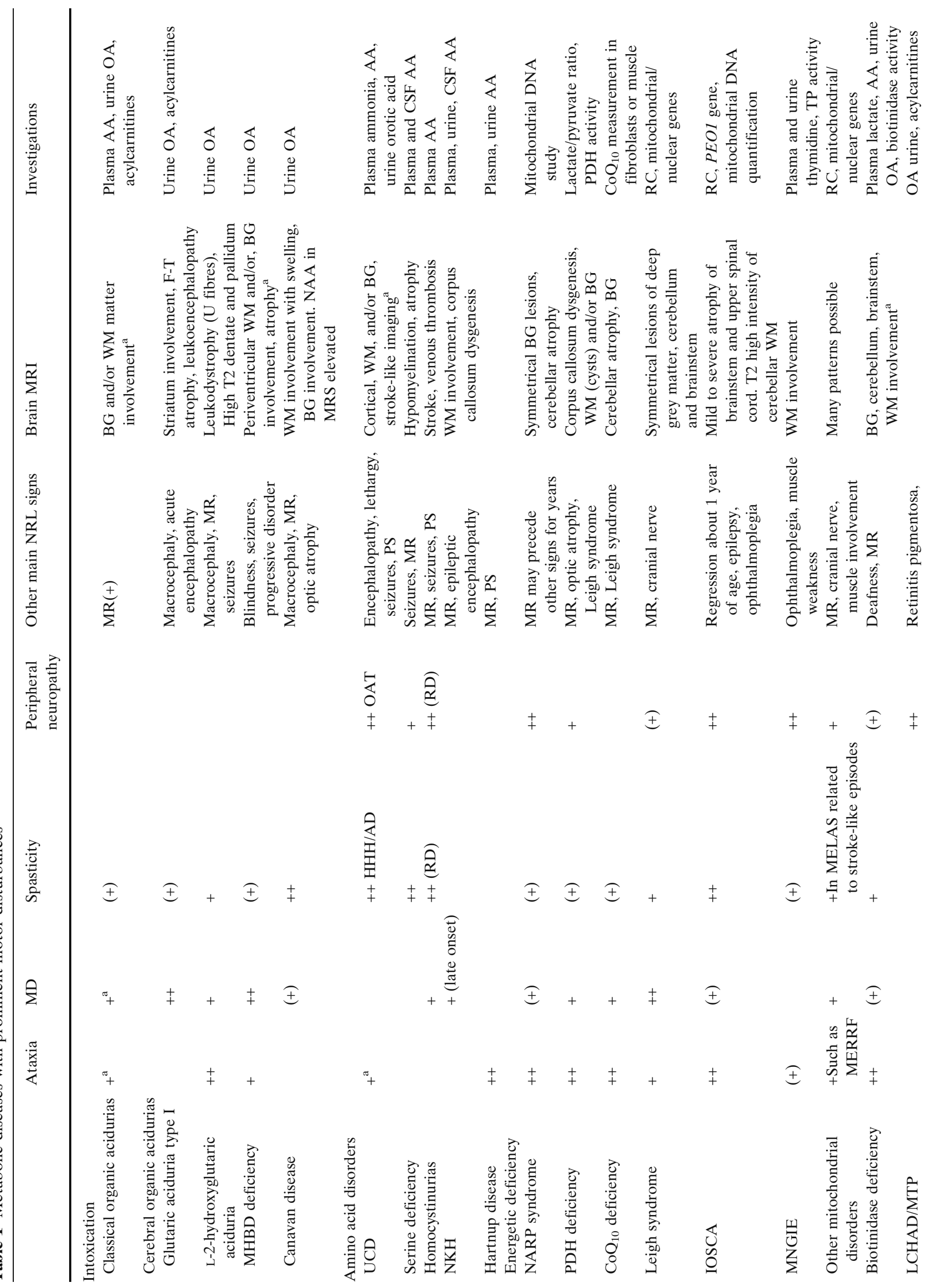




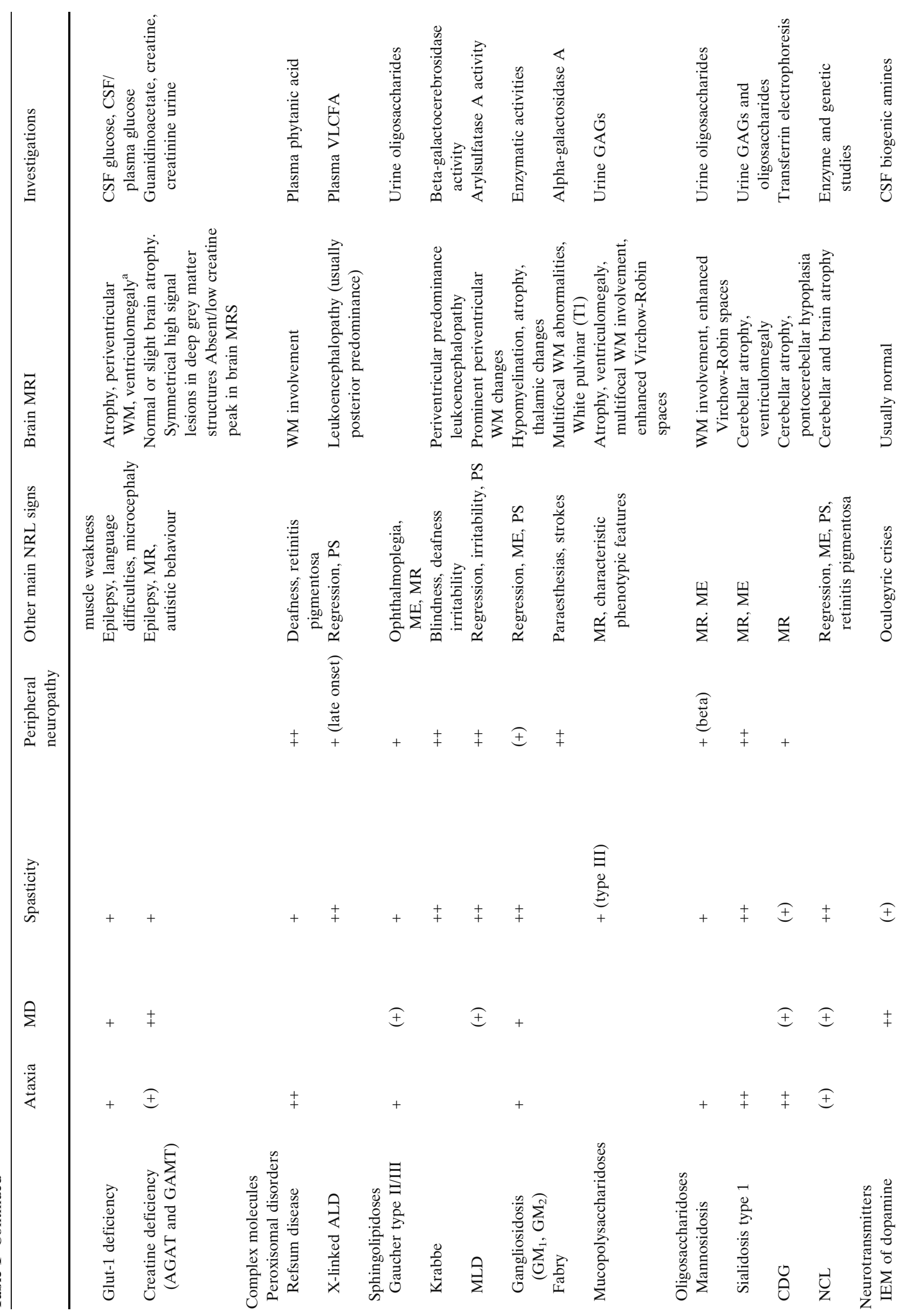




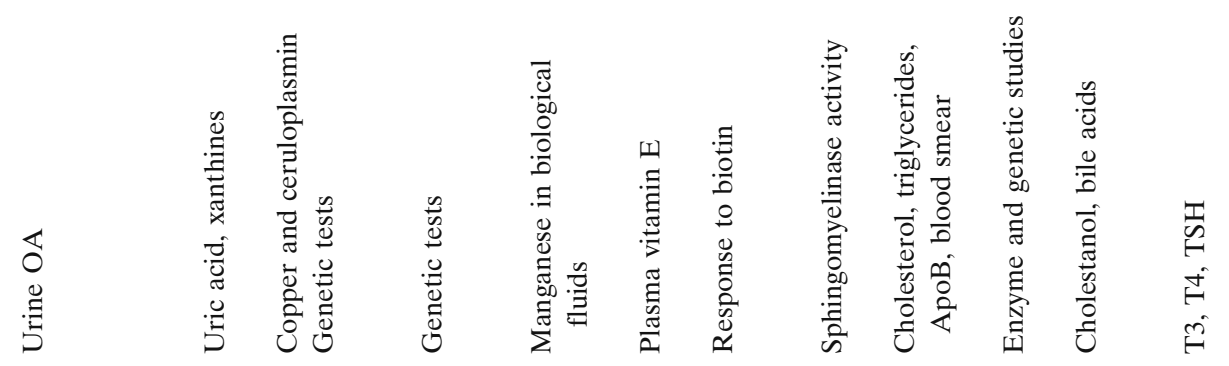

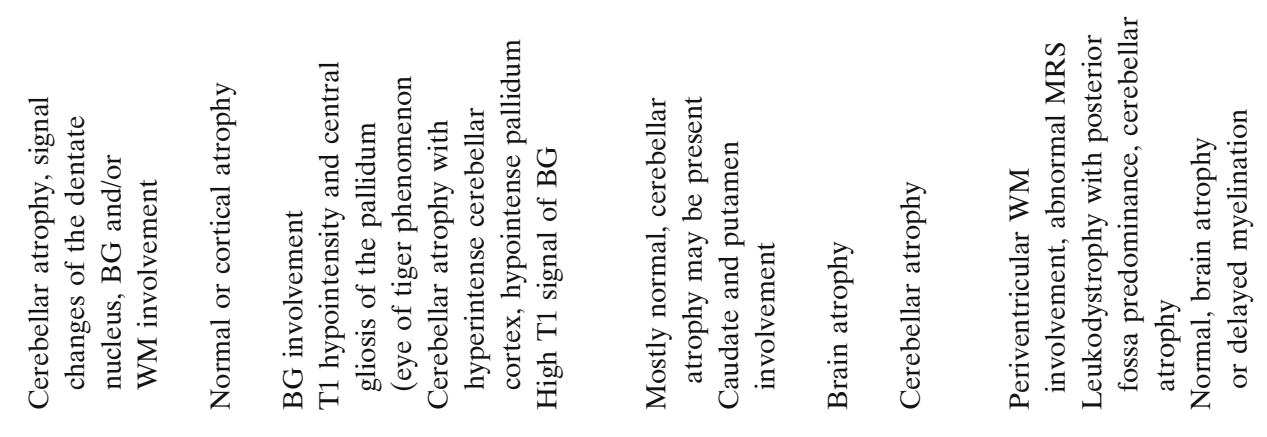

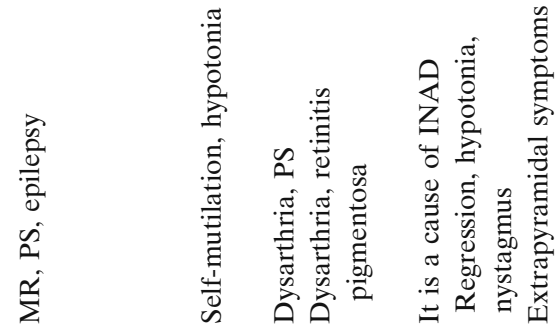

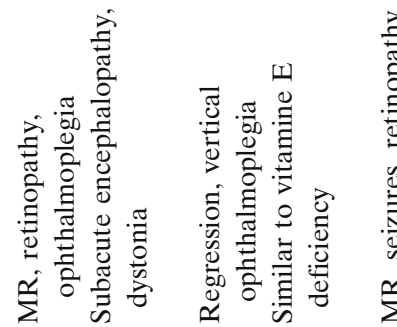

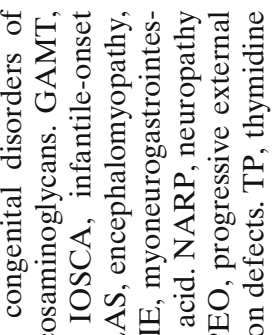

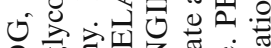
Uे कि

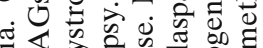
का

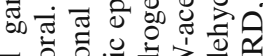
न

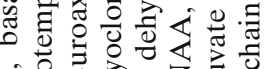

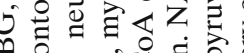

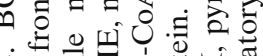

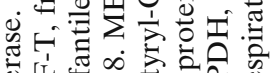

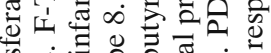

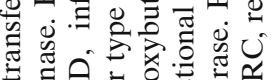
政过它

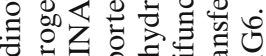

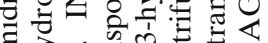

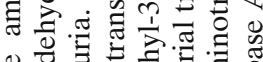

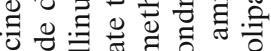

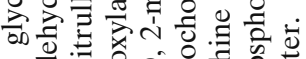

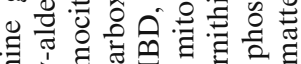

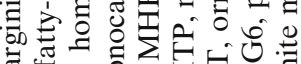

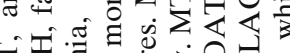

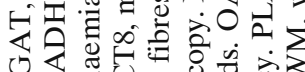

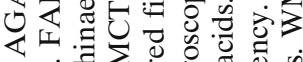

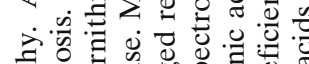

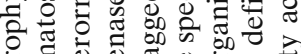

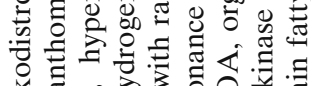

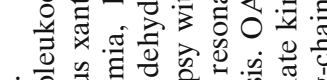

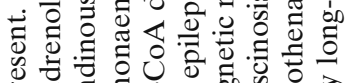

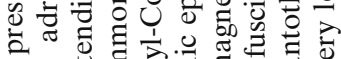

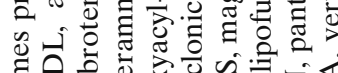

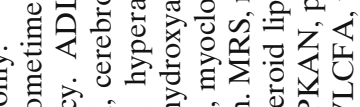
o

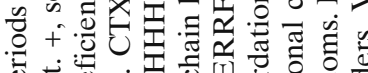

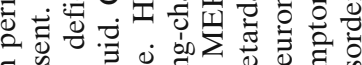

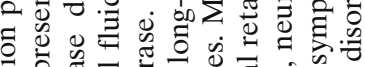

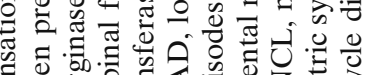

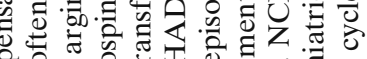

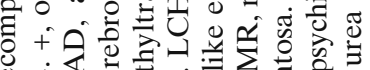

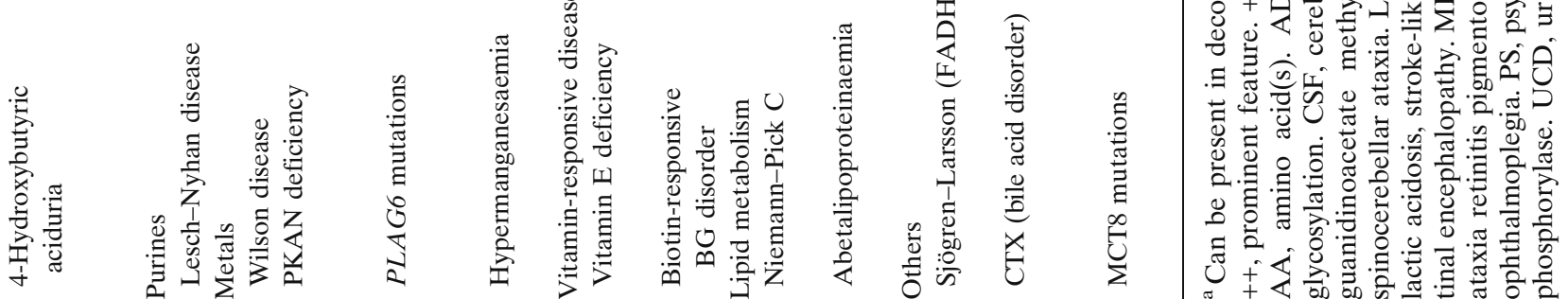




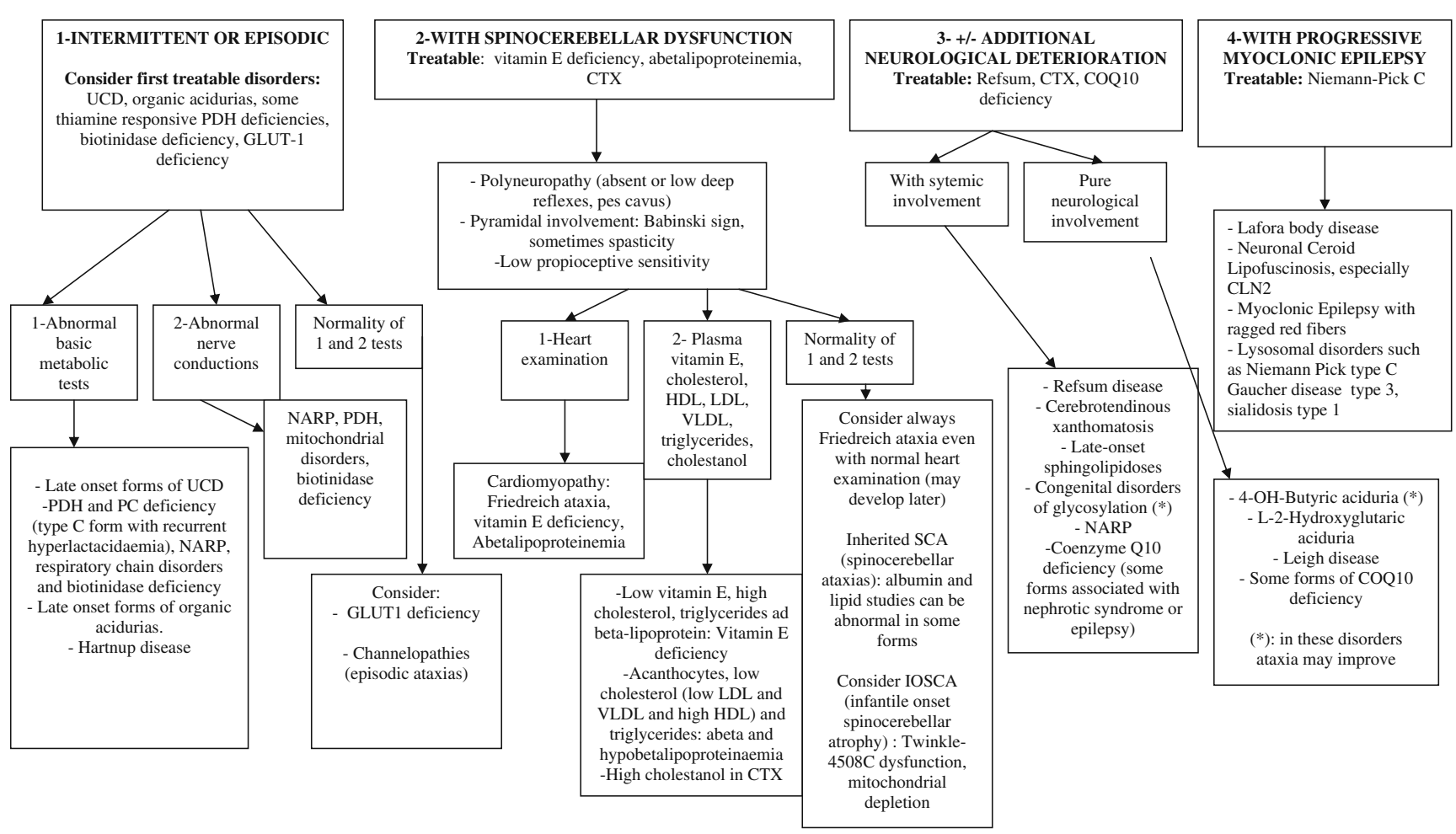

Fig. 1 Diagnostic approach for metabolic disorders with prominent ataxia

(especially early-onset forms) such as tyrosine hydroxylase, aromatic L-amino acid decarboxylase, and sepiapterin reductase deficiencies, biopterin defects with or without hyperphenylalaninaemia (Hyland et al. 2009), and the recently described mutations in the dopamine transporter gene. Contrary to the former diseases, this last disorder produces an elevated level of homovanillic acid in the CSF (Kurian et al. 2009). (2) Early-onset disorders of energy metabolism such as pyruvate carboxylase deficiency (Garcia-Cazorla et al. 2006), or some mitochondrial DNA defects (Davidzon et al. 2006). (3) Wilson disease with neurological manifestations has only exceptionally been related to early childhood, but mild neurological and neuropsychiatric disturbances are not unusual in this period of life. However, as Wilson disease is a treatable disorder, copper studies are strongly recommended from early school age. (4) Early onset rigid-akinetic syndrome has been recently associated with PLAG6 mutations (Kurian et al. 2008).

\section{Dystonia}

Dystonia is a major symptom in many different metabolic diseases. In fact, almost all neurometabolic disorders can cause dystonia at some stage, but glutaric aciduria type I, Leigh syndrome, and other mitochondrial cytopathies are among the most frequent.
If dystonia is focal, progresses slowly, or remains isolated over time, the most likely IEMs to be considered are primary dopaminergic deficiencies such as autosomal dominantly inherited GTP cyclohydrolase deficiency (Segawa disease; Segawa et al. 2003) or late-onset forms of tyrosine hydroxylase deficiency. By contrast, if the dystonia appears abruptly, settles rapidly, is generalized and postural from the very first stages of the disease, different metabolic causes should be strongly considered. Organic acidurias such as propionic aciduria and methylmalonic aciduria can develop dystonia during acute periods of decompensation, although in general, movement disorders are not a prominent sign in these disorders (Deodato et al. 2006). In many cases, dystonia develops late in the course of the disease, with focal onset and progressive generalization, causing major disability and wheelchair dependency (e.g. homocystinuria, NPC, GAMT deficiency). In NPC, isolated dystonia may appear as the first symptom before visceral involvement takes place. Glutaric aciduria type I and late-onset forms of gangliosidoses types I and II may present as progressive dystonia also (GouiderKhouja and Ben Youssef-Turki 2006). The distribution of dystonia may also be helpful to differentiate these disorders. For example, onset of dystonia in the lower limbs is frequent in primary dopaminergic deficiencies, whereas oromandibular dystonia is very characteristic of pantothenate kinase-associated neurodegeneration 


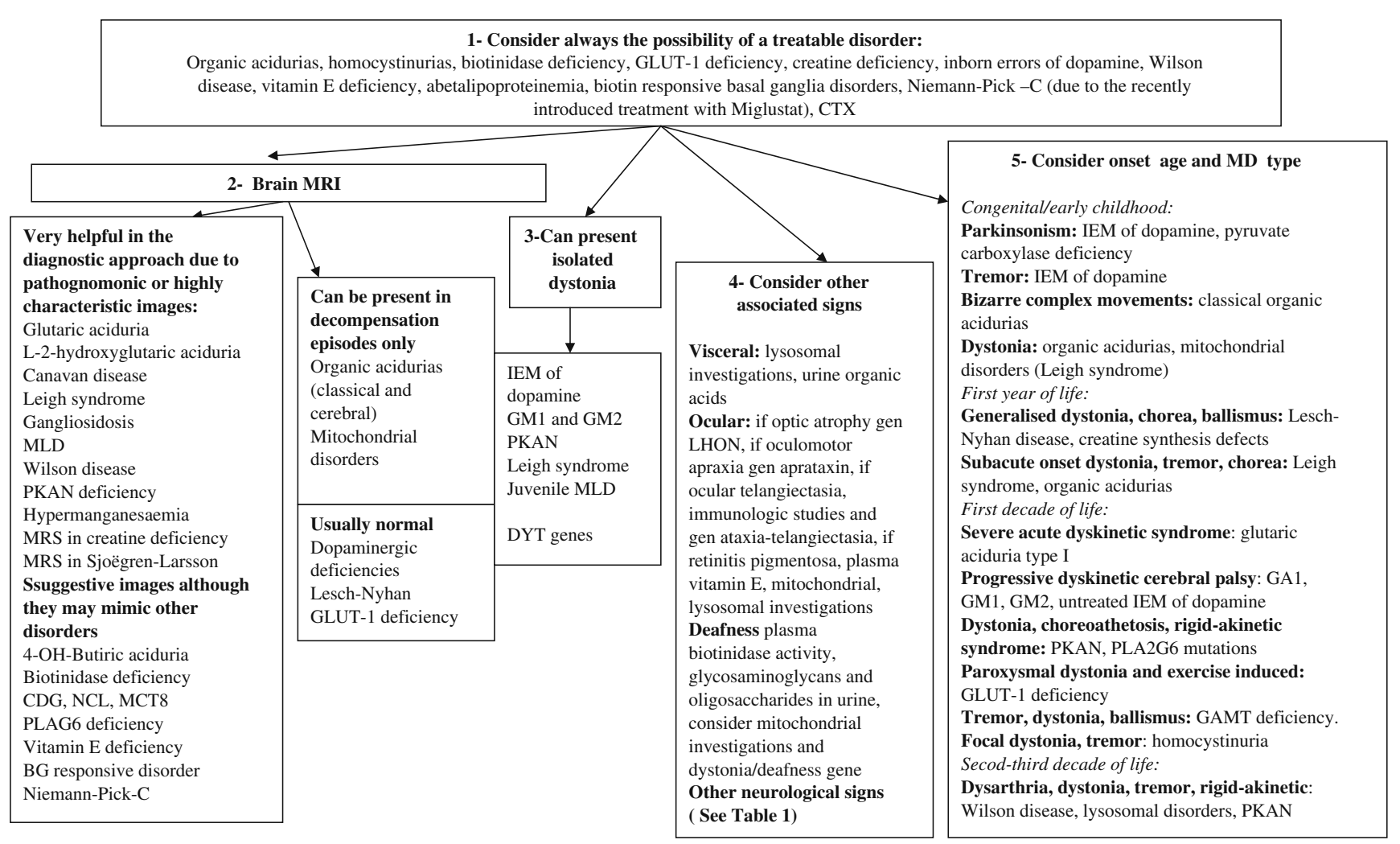

Fig. 2 Diagnostic approach for metabolic disorders with prominent movement disorders (MD) other than ataxias

(PKAN). Dystonia is a typical sign in PKAN in children (usually starting at around 5-6 years of age and often preceded by psychomotor delay), whereas the adult form manifests as rigid-akinetic syndrome.

Although other signs of neurological dysfunction usually coexist, some metabolic diseases can initially present as isolated dystonia (IEM of dopamine, gangliosidoses, PKAN, Leigh syndrome, pyruvate dehydrogenase deficiency, juvenile form of metachromatic leukodystrophy). Recently, a new phenotype of GLUT1 deficiency consisting of paroxysmal exerciseinduced dyskinesia has been described (Suls et al. 2008). Dystonic or choreoathetotic movements appear at a mean age of 8 years and are preceded by epileptic seizures in half of the patients. Paroxysmal exerciseinduced dyskinesia is usually triggered by a prolonged walk and lasts from few seconds to a few hours. Sugar administration or rest may improve the dyskinesia. In opposition to the classical phenotype of GLUT1 deficiency described by De Vivo et al. (1991), these patients are neurologically normal between episodes and show higher only borderline low glucose CSF/plasma ratios (mean 0.52 compared with a mean of 0.33 in classical phenotypes). It is now considered the most frequent genetic disease responsible for paroxysmal exerciseinduced dyskinesia. Haemolytic anaemia is another common laboratory finding in this condition. A

recently described disorder that causes dystonia is hypermanganesaemia associated with hepatic cirrhosis and polycythaemia. Brain MRI is especially helpful, showing high intensity of basal ganglia in T1-weighted images, suggesting accumulation of manganese (Tuschl et al. 2008). Figure 2 is a diagnostic approach to movement disorders (other than ataxia) in IEMs.

\section{IEM and spasticity}

Spasticity is a very common clinical situation in paediatric neurology. It results from damage to upper motor neurons or to the corticospinal tracts. Abnormal

Table 2 Clinical situations requiring CSF studies in patients presenting with predominant motor disturbances
- Unexplained diskinetic cerebral palsy

- Unexplained isolated dystonia or other type of movement disorder

- Unexplained rigid-akinetic syndrome

- Paroxysmal exerciseinduced dyskinesia

- Unexplained spastic paraparesis 
muscle contraction gives rise to muscle stiffness interfering with voluntary movements. Symptoms may vary from mild stiffness to severe muscle spasms and include hypertonia, brisk deep tendon reflexes, pathological reflexes, clonus, and weakness. In children, most events causing such motor damage occur during late pregnancy and delivery such as prematurity, neonatal asphyxia, birth trauma or infections. The resulting manifestations are usually grouped under the general term 'cerebral palsy'. Spasticity is the most common motor symptom in IEMs, but at the same time the least specific. It is usually associated with additional neurological findings or systemic involvement. However, some disorders can start with isolated spastic paraparesis such as X-linked adrenoleukodystrophy, homocysteine remethylation defects, the hyperammonaemia-hyperornithinaemia-homocitrullinuria $(\mathrm{HHH})$ syndrome, arginase deficiency, or Segawa disease. This possibility of an IEM should be considered in every child with the diagnosis of cerebral palsy but without history and MRI findings of perinatal or postnatal brain injury. In the diagnostic approach (Fig. 3) it is crucial to consider brain MRI findings. White-matter abnormalities and their main neuroradiological characteristics can be extremely helpful (Schiffmann and van der Knaap 2009) and allow diagnosis in certain cases, eliminating the need for much unnecessary metabolic and genetic testing. Other associated symptoms such as peripheral neuropathy also contribute to making a more specific differential diagnosis.

\section{Treatable IEMs with diparesis/tetraparesis}

Urea cycle disorders such as arginase deficiency can result in progressive spasticity, seizures, and mental retardation despite relatively mild hyperammonaemia. Sodium phenylbutyrate and dietary arginine restriction are effective therapeutic tools (Scaglia and Lee 2006). $\mathrm{HHH}$ syndrome is a disorder of ornithine transport between cytoplasm and mitochondria that causes progressive spastic diplegia and other signs of neurological dysfunction (Salvi et al. 2001). Therapeutic strategies include diet and ammonium-lowering agents.

Biotinidase deficiency may also cause progressive spastic paraparesis that improves with biotin administration (5-20 mg/day) (Ramaekers et al. 1993). Defects of homocysteine remethylation can cause demyelination of the pyramidal tracts and subacute combined degeneration of the spinal cord (Surtees 1998). It is important to measure plasma amino acids, total homocysteine and folate concentrations in every patient with isolated spasticity, as it may be the leading or only clinical sign for a long period. Patients treated

\begin{tabular}{|c|c|c|c|}
\hline \multicolumn{4}{|c|}{$\begin{array}{l}\text { 1- Consider always the possibility of a treatable disorder: } \\
\text { HHH, Biotinidase deficiency, Homocysteine remethylation defects, untreated PKU, some forms of dopaminergic deficiency, CTX, CFD, } \\
\text { vitamin E deficiency, abetalipoproteinemia, serine deficiency }\end{array}$} \\
\hline \multicolumn{2}{|l|}{ 2- Brain MRI } & \multirow{3}{*}{$\begin{array}{l}\text { 3-Nerve conduction studies } \\
\text { Demyelinating neuropathy } \\
\text { Lysosomal disorders such as } \\
\text { MLD, Krabbe disease, beta- } \\
\text { mannosidosis, sialidosis, } \\
\text { Gaucher disease, Niemann-Pick } \\
\text { C, Refsum and other } \\
\text { peroxisomal disorders, MNGIE, } \\
\text { CTX, Vitamin E deficiency } \\
\text { Axonal neuropathy } \\
\text { Biotinidase deficiency, } \\
\text { homocysteine remethylation } \\
\text { defects, vitamin E deficiency, } \\
\text { serine deficiency, CTX, CDG, } \\
\text { mitochondrial disorders, PDH, } \\
\text { NARP, porphyria, some } \\
\text { peroxisome biogenesis } \\
\text { disorders } \\
\text { Small fibres } \\
\text { Fabry disease } \\
\text { Anteriorn horn cell disease } \\
\text { Mitochondrial depletion } \\
\text { syndromes, peroxysomal } \\
\text { disorders, GM2, biotinidase } \\
\text { deficiency, homocysteine } \\
\text { remethylation defects, INAD } \\
\text { (PLA2G6 mutations), }\end{array}$} & \multirow{3}{*}{$\begin{array}{l}\text { 4- Consider other associated signs } \\
\text { Visceral: HHH (liver involvement, } \\
\text { cyclic vomiting), CTX (diarrhoea), X- } \\
\text { linked adrenoleukodystrophy (adrenal } \\
\text { insufficiency), many lysosomal } \\
\text { disorders (organomegaly) } \\
\text { Cutaneous signs: CTX (xanthomas), } \\
\text { multiple sulphatase deficiency and } \\
\text { Sjöegren-Larsson (ichthyosis), } \\
\text { biotinidase deficiency (alopecia, } \\
\text { dermatitis), X-linked } \\
\text { adrenoleukodystrophy (melanoderma), } \\
\text { sialidosis II (angiokeratoma) } \\
\text { Ocular signs: Homocysteine } \\
\text { remethylation defects, (retinitis } \\
\text { pigmentosa, optic nerve atrophy), CTX } \\
\text { (cataracts), biotinidase deficiency, } \\
\text { (optic neuropathy), Sjöegren-Larsson } \\
\text { (retinopathy), cerebral folate deficiency } \\
\text { (optic atrophy), different lysosomal } \\
\text { disorders (cherry red spot), brain iron } \\
\text { disease, mitochondrial disorders, } \\
\text { vitamin E deficiency (retinitis } \\
\text { pigmentosa) } \\
\text { Additional NRL signs: see table } 1\end{array}$} \\
\hline $\begin{array}{l}\text { WM T2 hyperintensity images + T1 } \\
\text { hypointensity (most of them } \\
\text { demyelinating): } \\
\text { A) Confluent: } \\
\text {-Frontal predominance: MLD, }\end{array}$ & $\begin{array}{l}\text { Hypomyelination } \\
\text { Sialic acid storage } \\
\text { Fucosidosis } \\
\text { Serine synthesis defects } \\
\text { Early onset GM1,GM2, infantile NCL, } \\
\text { Alpers syndrome }\end{array}$ & & \\
\hline $\begin{array}{l}\text { disease } \\
\text {-Periventricular predominance: MLD, } \\
\text { Krabbe, Sjöegren-Larsson } \\
\text {-Parieto-occipital predominance: Krabbe, } \\
\text { X-ALD, peroxisomal disorders, neonatal } \\
\text { NKH } \\
\text {-Subcortical predominance: Canavan } \\
\text { disease, Kearns-Sayre syndrome, L-2- } \\
\text { hydroxyglutaric aciduria } \\
\text {-Posterior fossa predominance: CTX, } \\
\text { peroxisomal disorders } \\
\text {-Brain stem: peroxisomal disorders, } \\
\text { Wilson, Leigh syndrome } \\
\text {-Diffuse cerebral: some mitochondrial } \\
\text { disorders, end-stage of progressive } \\
\text { disorders } \\
\text { B) Multifocal: Fabry disease, some } \\
\text { mitochondrial disorders, } \\
\text { mucopolysaccharidoses, L-2- } \\
\text { hydroxylglutaric aciduria }\end{array}$ & $\begin{array}{l}\text { Prominent global or supratentorial } \\
\text { atrophy: Early onset GM1, GM2, } \\
\text { infantile NCL, other neurodegenerative } \\
\text { disorders } \\
\text { Cerebellar atrophy: } \\
\text { INAD (hyperintense cerebellar cortex), } \\
\text { mitochondrial disorders, sialic acid } \\
\text { storage disease, biotinidase deficiency } \\
\text { Basal ganglia and thalamic } \\
\text { abnormalities: } \\
\text { Leigh syndrome, gangliosidoses, } \\
\text { infantile NCL, biotinidase deficiency } \\
\text { Cortical abnormalities: } \\
\text { Alpers disease, IOSCA, MELAS, } \\
\text { global atrophy in many } \\
\text { neurodegenerative disorders } \\
\text { Usually normal: } \\
\text { Neurotransmitter defects, Lesch-Nyhan } \\
\text { syndrome, vitamine E deficiency, } \\
\text { (cerebellar atrophy may be present) }\end{array}$ & & \\
\hline
\end{tabular}

Fig. 3 Diagnostic approach for metabolic disorders with prominent spasticity 
with a combination of betaine (up to $10 \mathrm{~g} / \mathrm{day}$ in 3 doses), folic acid (5-10 mg/day), and hydroxycobalamin $(0.5-1 \mathrm{mg} /$ day orally or $1 \mathrm{mg}$ i.m. monthly) from the neonatal period may develop normally (Strauss et al. 2007), whereas late-treated patients show at most a partial recovery of the neurological signs together with an improvement of cerebral myelination on MRI (Surtees et al. 1991). This combination of betaine is not as effective as it is in resolving other neurological or psychiatric symptoms related to the defect. Untreated phenylketonuria and a recently described cerebral folate deficiency syndrome (Ramaekers et al. 2005), although the latter is still not clearly defined, are other examples of treatable IEMs that may exhibit progressive spasticity without treatment. Cerebrotendinous xanthomatosis may present with progressive spasticity from the second decade of life if appropriate treatment has not been initiated during early stages of the disease (Verrips et al. 2000).

Dopamine synthesis defects, especially autosomal dominant GTP cyclohydrolase I deficiency, may exhibit pyramidal tract signs. In some cases, lower limb dystonia can mimic spastic paraparesis. Therefore, CSF studies and a trial of levodopa, should be performed in all patients with unexplained spastic paraparesis or dystonic cerebral palsy (Hyland et al. 2009). In vitamin E deficiency, spasticity may appear together with ataxia, peripheral neuropathy, and retinitis pigmentosa.

Progressive spasticity associated with additional neurologic signs, irritability, and global deterioration

This group of heterogeneous disorders usually results in complex neurological pictures, in which progressive spasticity is only one of the main features. Peripheral neuropathy and visual, auditory, and visceral involvement are frequently present. Brain MRI may reveal specific white-matter lesions (Fig. 3).

Lysosomal disorders and X-linked adrenoleukodystrophy share these characteristics and are well described elsewhere (Desnick and Schindler 2001; Moser 1997). Infantile neuroaxonal dystrophy (INAD) and related disorders are due to mutated PLA2G6, encoding a phospholipase. They manifest with progressive neurological regression and distended axons (spheroid bodies) in the nervous system and increased iron deposition in basal ganglia. Progressive spastic tetraparesis, extrapyramidal signs, dementia, retinitis pigmentosa, and optic atrophy are frequently present (Morgan et al. 2006). The first signs are nystagmus, hypotonia, and ataxia.

Pyramidal tract involvement is also frequent in mitochondrial disorders, but other signs and symptoms often guide the diagnostic approach (Table 1).
Some cerebral organic acidurias such as Canavan disease (high urine and brain MRS $N$-acetylaspartate) (Lyon et al. 2006) or L-2-hydroxyglutaric aciduria are examples of childhood leukodystrophies exhibiting different degrees of progressive spasticity and welldefined brain MRI patterns (Schiffmann and van der Knaap 2009).

\section{Other signs}

Other associated signs, especially cutaneous and ocular, can provide important clues to the diagnosis (Fig. 3).

\section{IEMs presenting mainly as peripheral neuropathy}

The peripheral nerves make up an intricate network that connects the brain and spinal cord to the muscles, skin, and internal organs. Peripheral neuropathies can be acute or chronic, involving large or small fibres, be demyelinating or axonal, the latter being differentiated by electrodiagnostic studies or nerve biopsy. In IEMs the peripheral nerves may affect the structure or function of myelin and axons due to metabolic pathway dysregulation or storage.

Acute polyneuropathies mimicking Guillain-Barré syndrome can be observed in acute attacks of porphyrias (Sedel et al. 2007), in patients with tyrosinaemia type I (Mitchell et al. 1990) and in pyruvate dehydrogenase deficiency (Debray et al. 2006).

Chronic axonal polyneuropathy is the most common form of peripheral neuropathy in IEMs. Many metabolic disorders may cause this form of neuropathy (Sedel et al. 2007). Treatable disorders are biotinidase deficiency, homocysteine remethylation defects, ornithine aminotransferase deficiency, vitamin E deficiency, serine deficiency, Wilson disease, and cerebrotendinous xanthomatosis (Sedel et al. 2007). Neuromyopathic forms of trifunctional protein deficiency can produce progressive polyneuropathy and limb girdle myopathy with recurrent episodes of rhabdomyolysis (Spiekerkoetter et al. 2004). Chronic sensorimotor polyneuropathy is the most common form of peripheral neuropathy associated with mitochondrial disorders. However, various other forms have been reported (Bouillot et al. 2002). NARP, SANDO (sensory ataxic neuropathy, dysarthria, and ophthalmoparesis), and MNGIE (myoneurogastrointestinal encephalopathy) are among the most common mitochondrial disorders that are associated with neuropathy. Long-chain fatty acid oxidation defects (LCHAD) present with peripheral sensorimotor polyneuropathy and pigmentary retinitis as 
late complications of the disease (Saudubray et al. 1999).

Chronic demyelinating polyneuropathy is a common feature in some lysosomal diseases involving myelin metabolism (such as metachromatic leukodystrophy and Krabbe disease), peroxisomal disorders (Wanders 2004), and some mitochondrial disorders such as MNGIE due to thymidine phosphorylase gene mutations (Needham et al. 2007).

In Fabry disease, painful acroparaesthesias with dysautonomic features is a sign of small-fibre peripheral neuropathy (Lacomis et al. 2005).

Lower motor neuron disease refers to any disease involving spinal or bulbar motor neurons. Muscle weakness and atrophy, cramps, and fasciculations are the main clinical features. In children, lower motor neuron disease has been described in peroxisomal biogenesis defects (Baumgartner et al. 1998) and mitochondrial depletion syndromes, especially thymidine kinase 2 deficiency (Oskoui et al. 2006; Pons et al. 1996). Anterior horn cell disease is also one of the features of infantile neuroaxonal dystrophy (INAD), recently related to PLAG6 mutations (Kurian et al. 2008).

\section{References}

Assmann B, Surtees R, Hoffmann GF (2003) Approach to the diagnosis of neurotransmitter diseases exemplified by the differential diagnosis of childhood-onset dystonia. Ann Neurol 54(Suppl 6):S18-24

Baumgartner MR, Verhoeven NM, Jakobs C et al (1998) Defective peroxisome biogenesis with a neuromuscular disorder resembling Werdnig-Hoffmann disease. Neurology. 51:1427-1432

Bouillot S, Martin-Négrier ML, Vital A et al (2002) Peripheral neuropathy associated with mitochondrial disorders: 8 cases and review of the literature $J$ Peripher Nerv Syst 7:213-220

Buccoliero R, Palmeri S, Federico A (2003) Ataxia, myoclonus and macular degeneration. Orphanet. http://www.orpha.net/ data/patho/GBuk-ataxiamyoclonus.pdf

Davidzon G, Greene P, Mancuso M et al (2006) Early-onset familial Parkinsonism due to POLG mutations. Ann Neurol 59:859-862

Debray FG, Lambert M, Vanasse M et al (2006) Intermittent peripheral weakness as the presenting feature of pyruvate dehydrogenase deficiency. Eur J Pediatr 165:462-466

Deodato F, Boenzi S, Santorelli FM, Dionisi-Vici C. (2006) Methylmalonic and propionic aciduria. Am J Med Genet C Semin Med Genet 142C:104-112

Desnick RJ, Schindler D (2001) Alpha-N-acetylgalactosaminidase deficiency: Schindler disease. In: Scriver CR, Beaudet al Sly WS, Valle D (eds); Childs B, Kinzler KW, Vogelstein B (assoc. eds) The metabolic and molecular bases of inherited disease, 8th edn. McGraw-Hill, New York, pp 3483-3505

De Vivo DC, Trifiletti RR, Jacobson RI, Ronen GM, Behmand RA, Harik SI (1991) Defective glucose transport across the blood-brain barrier as a cause of persistent hypoglycorrhachia, seizures, and developmental delay. N Engl J Med 325 (10):703-709
Espinós C, Pineda M, Martínez-Rubio D (2009) Mutations in the urocanase gene UROC1 are associated with urocanic aciduria. J Med Genet (in press)

Fernández-Alvarez E, General concepts In: Fernández-Alvarez E, Aicardi J (eds) (2001) Movement disorders in children. MacKeith Press, London, pp 1-23

Garcia-Cazorla A, Rabier D, Touati G et al (2006) Pyruvate carboxylase deficiency: metabolic characteristics and new neurological aspects. Ann Neurol 59:121-127

Gouider-Khouja N, Ben Youssef-Turki I (2006) [Type I glutaric aciduria: an unrecognized cause of progressive dystonia] Rev Neurol (Paris) 162(8-9):858-861

Hakonen AH, Goffart S, Marjavaara S et al (2008) Infantile-onset spinocerebellar ataxia and mitochondrial recessive ataxia syndrome are associated with neuronal complex I defect and mtDNA depletion. Hum Mol Genet 17(23):3822-3835

Hoffmann GF, Surtees RA, Wevers RA (1998) Cerebrospinal fluid investigations for neurometabolic disorders. Neuropediatrics 29:59-71

Holmgren G, Brundin A, Gustavson KH, Sjögren S, Kleijer WJ, Niermeijer MF (1980) Intermittent neurological symptoms in a girl with a maple syrup urine disease (MSUD) variant. Neuropediatrics 11(4):377-383

Homer VM, George PM, Du Toit S, Davidson JS, Wilson CJ (2005) Mental retardation and ataxia due to normotriglyceridemic hypobetalipoproteinemia. Ann Neurol 58:160-163

Hyland K, Gibson KM, Sharma R, Van Hove JLK, Hoffmann GF (2009) Neurotransmitter disorders. In: Sarafoglu K, Hoffmann GF, Roth K (eds). Pediatric endocrinology and inborn errors of metabolism. McGraw-Hill, New York, pp 789-820

Jen JC (2008) Hereditary episodic ataxias. Ann N Y Acad Sci 1142:250-253

Kleta R, Romeo E, Ristic Z et al (2004) Mutations in SLC6A19, encoding B0AT1, cause Hartnup disorder. Nat Genet 36 (9):999-1002

Kurian MA, Morgan NV, MacPherson L et al (2008) Phenotypic spectrum of neurodegeneration associated with mutations in the PLA2G6 gene. Neurology 70(18):1623-1629

Kurian MA, Zhen J, Cheng SY et al (2009) Homozygous loss-offunction mutations in the gene encoding the dopamine transporter are associated with infantile parkinsonismdystonia. J Clin Invest 119(6):1595-1603

Lacomis D, Roeske-Anderson L, Mathie L (2005) Neuropathy and Fabry's disease. Muscle Nerve 31:102-107

Lyon G, Fattal-Valevski A, Kolodny EH (2006) Leukodystrophies: clinical and genetic aspects. Top Magn Reson Imaging. 17:219-242

Mariotti C, Gellera C, Rimolid M et al (2004) Ataxia with isolated vitamin $\mathrm{E}$ deficiency: neurological phenotype, clinical follow-up and novel mutations in TTPA gene in Italian families. Neurol Sci 25:130-137

Marzouki N, Benomar A, Yahyaoui M et al (2005) Vitamin E deficiency ataxia with (744 del A) mutation on alpha-TTP gene: genetic and clinical peculiarities in Moroccan patients. Eur J Med Genet 48:21-28

Mitchell G, Larochelle J, Lambert M et al (1990) Neurologic crises in hereditary tyrosinemia. N Engl J Med 322:432-437

Morgan NV, Westaway SK, Morton JE et al (2006) PLA2G6, encoding a phospholipase A2, is mutated in neurodegenerative disorders with high brain iron. Nat Genet 38:752-754

Moser H (1997) Adrenoleukodystrophy: phenotype, genetics, pathogenesis and therapy. Brain 120:1485-1508

Needham M, Duley J, Hammond S, Herkes GK, Hirano M, Sue CM (2007) Mitochondrial disease mimicking CharcotMarie-Tooth disease. J Neurol Neurosurg Psychiatry 78:99100 
Oskoui M, Davidzon G, Pascual J et al (2006) Clinical spectrum of mitochondrial DNA depletion due to mutations in the thymidine kinase 2 gene. Arch Neurol 63:1122-1126

Overweg-Plandsoen WC, Groener JE et al (2003) GLUT-1 deficiency without epilepsy-an exceptional case. J Inherit Metab Dis 26:559-563

Pons R, Andreetta F, Wang CH et al (1996) Mitochondrial myopathy simulating spinal muscular atrophy. Pediatr Neurol 15:153-158

Poretti A, Wolf NI, Boltshauser E (2008) Differential diagnosis of cerebellar atrophy in childhood. Eur J Paediatr Neurol 12 (3):155-167

Prasad A, Greenberg C, Prasad C (2005) Ataxia with identified genetic and biochemical defects. (2005) Geneclinics. http:// www.emedicine.com/neuro/topic556.htm. Accessed 25 July 2009.

Ramaekers VT, Brab M, Rau G, Heimann G (1993) Recovery from neurological deficits following biotin treatment in a biotinidase $K_{\mathrm{m}}$ variant. Neuropediatrics 24:98-102

Ramaekers VT, Rothenberg SP, Sequeira JM et al (2005) Autoantibodies to folate receptor in the cerebral folate deficiency syndrome. $N$ Engl J Med 352:1985-1991

Robinson BH, MacKay N, Chun K, Ling M (1996) Disorders of pyruvate carboxylase and the pyruvate dehydrogenase complex. J Inherit Metab Dis 19(4):452-462

Salvi S, Santorelli FM, Bertini E et al (2001) Clinical and molecular findings in hyperornithinemia-hyperammonemiahomocitrullinuria syndrome. Neurology 57(5):911-914

Saudubray JM, Martin D, de Lonlay P et al (1999) Recognition and management of fatty acid oxidation defects: a series of 107 patients. J Inherit Metab Dis 22(4):488-502

Scaglia F, Lee B (2006) Clinical, biochemical, and molecular spectrum of hyperargininemia due to arginase I deficiency. Am J Med Genet C Semin Med Genet 142:113-120

Schiffmann R, van der Knaap MS (2009) Invited article: an MRI-based approach to the diagnosis of white matter disorders. Neurology 72(8):750-759

Sedel F, Barnerias C, Dubourg O, Desguerres I, Lyon-Caen O, Saudubray JM (2007) Peripheral neuropathy and inborn errors of metabolism in adults. $J$ Inherit Metab Dis 30:642653

Segawa M, Nomura Y, Nishiyama N (2003) Autosomal dominant guanosine triphosphate cyclohydrolase I deficiency (Segawa disease) Ann Neurol 54(Suppl 6):S32-45

Siebner HR, Berndt S, Conrad B (1996) Cerebrotendinous xanthomatosis without tendon xanthomas mimicking Marinesco-Sjoegren syndrome: a case report. J Neurol Neurosurg Psychiatry 60(5):582-585

Spiekerkoetter U, Bennett MJ, Ben-Zeev B, Strauss AW, Tein I (2004) Peripheral neuropathy, episodic myoglobinuria, and respiratory failure in deficiency of the mitochondrial trifunctional protein. Muscle Nerve 29:66-72

Strauss KA, Morton DH, Puffenberger EG et al (2007) Prevention of brain disease from severe 5,10-methylenetetrahydrofolate reductase deficiency. Mol Genet Metab 91 (2):165-175

Suls A, Dedeken P, Goffin K et al (2008) Paroxysmal exerciseinduced dyskinesia and epilepsy is due to mutations in SLC2A1, encoding the glucose transporter GLUT1. Brain 131(Pt 7):1831-44

Surtees R (1998) Demyelination and inborn errors of the single carbon transfer pathway. Eur J Pediatr 157:S118-S121

Surtees R, Leonard J, Austin S (1991) Association of demyelination with deficiency of cerebrospinal-fluid $S$-adenosylmethionine in inborn errors of methyl-transfer pathway. Lancet 338:8782-87831550-1554

Tuschl K, Mills PB, Parsons H et al (2008) Hepatic cirrhosis, dystonia, polycythaemia and hypermanganesaemia-a new metabolic disorder. J Inherit Metab Dis 31(2):151163

Verrips A, Hoefsloot LH, Steen Bergen GC et al (2000) Clinical and molecular genetic characteristics of patients with cerebrotendinous xanthomatosis. Brain 123:908-919

Wanders RJ (2004) Peroxisomes, lipid metabolism, and peroxisomal disorders. Mol Genet Metab 83:16-27

Wang D, Pascual JM, Yang $\mathrm{H}$ et al (2005) Glut-1 deficiency syndrome: clinical, genetic, and therapeutic aspects. Ann Neurol 57(1):111-118 